\title{
Factores de la delincuencia juvenil en el Perú desde el enfoque preventivo*
}

\section{Juvenile delinquency factors in Peru from a preventive approach}

\author{
FREDdY CCOPA-QUISPE** \\ DORIS FUSTER-GUILLÉN *** \\ KATELINEN RIVERA-PAIPAY**** \\ YADIRI PEJeRREY-RIVAS***** \\ Miguel Tupac Yupanqui-Bustamante ${ }^{* * * * * *}$
}

\section{Resumen}

Objetivo. La presente investigación tiene por objetivo identificar los factores e indicadores predominantes que provocan que la juventud cometa actos delincuenciales en el distrito de Villa María del Triunfo. Metodología. El estudio desarrollado se enmarca en el modelo positivista-cuantitativo, de tipo sustantivo. El diseño de investigación fue no experimental, el corte del estudio fue transversal, y el nivel descriptivo-explicativo. La muestra estuvo constituida por 93 jóvenes que formaban parte de pandillas. La técnica fueron la entrevista y la encuesta. Los instrumentos utilizados fueron la guía de entrevistas no estructurada y el cuestionario. Este último obtuvo una fiabilidad de 0,929 obtenidas a través del Alfa de Cronbach. Resultados. Los resultados se procesaron a través de la regresión logística, la misma que establece que el factor predominante es el factor social con un $(B=0,856)$ presenta mayor coeficiente, entonces esto conduce a los actos delictivos en los jóvenes. Conclusión. El indicador que tiene mayor peso dentro de lo social que conduce a la delincuencia juvenil es la falta de participación de jóvenes en las juntas vecinales y ello hace que no se involucren ni se preocupen por otros.

Palabras clave: acciones delictivas, delincuencia juvenil, prevención de la delincuencia.

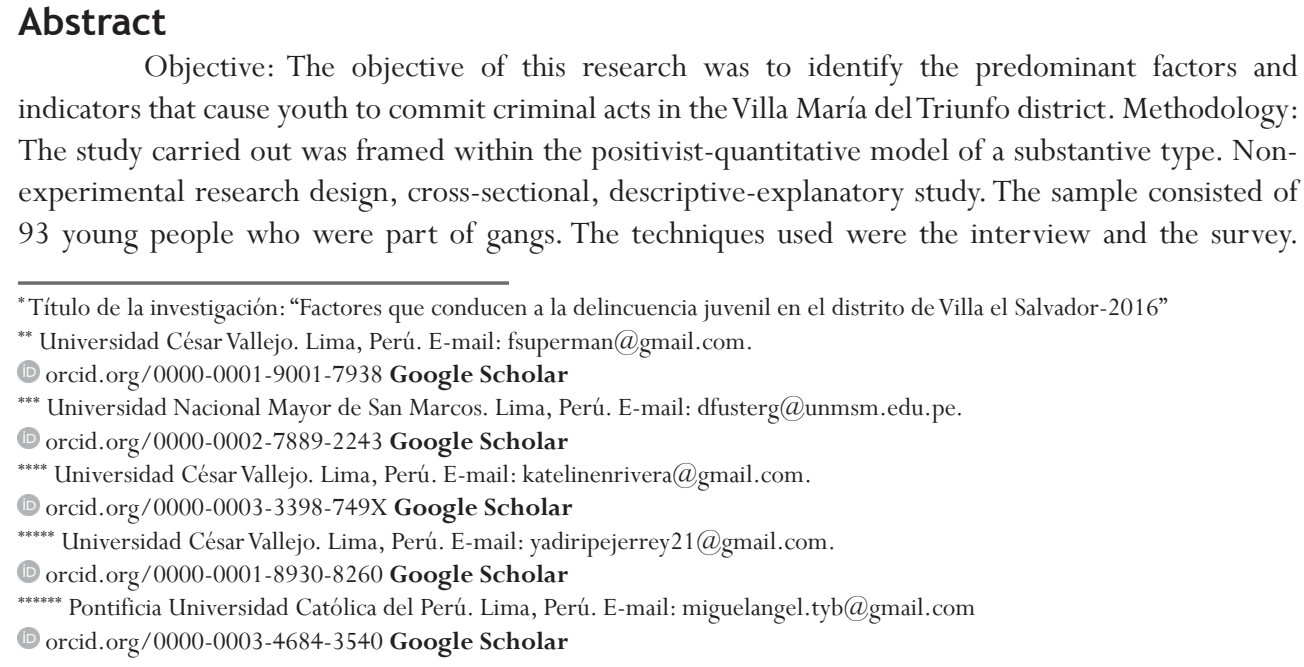

Objective: The objective of this research was to identify the predominant factors and indicators that cause youth to commit criminal acts in the Villa María del Triunfo district. Methodology: The study carried out was framed within the positivist-quantitative model of a substantive type. Nonexperimental research design, cross-sectional, descriptive-explanatory study. The sample consisted of 93 young people who were part of gangs. The techniques used were the interview and the survey.

\footnotetext{
*Título de la investigación: "Factores que conducen a la delincuencia juvenil en el distrito de Villa el Salvador-2016"

${ }^{* * *}$ Universidad César Vallejo. Lima, Perú. E-mail: fsuperman@gmail.com.

(D) orcid.org/0000-0001-9001-7938 Google Scholar

**** Universidad Nacional Mayor de San Marcos. Lima, Perú. E-mail: dfusterg@unmsm.edu.pe.

(D) orcid.org/0000-0002-7889-2243 Google Scholar

${ }^{* * * * *}$ Universidad César Vallejo. Lima, Perú. E-mail: katelinenrivera@gmail.com.

(D) orcid.org/0000-0003-3398-749X Google Scholar

****** Universidad César Vallejo. Lima, Perú. E-mail: yadiripejerrey21@gmail.com.

(D) orcid.org/0000-0001-8930-8260 Google Scholar

******* Pontificia Universidad Católica del Perú. Lima, Perú. E-mail: miguelangel.tyb@gmail.com

(D) orcid.org/0000-0003-4684-3540 Google Scholar
} 
Factores de la delincuencia juvenil en el Perú desde el enfoque preventivo

The instruments used were the unstructured interview guide and the questionnaire. The latter got a reliability of 0.929 obtained through Cronbach's Alpha measure. Results: The results were processed through logistic regression, the same that establishes that the predominant factor is the social factor with a $(B=0.856)$ presenting a higher coefficient which leads to criminal acts in young people. Conclusion: The indicator that has the greatest weight in the social sphere that leads to juvenile delinquency is the lack of participation of young people in neighborhood councils which means that they do not get involved or worry about others.

Key words: criminal actions, juvenile delinquency, crime prevention.

\section{Introducción}

El ejercicio de la violencia se considera un hecho social incontrolable que en estos últimos tiempos va incrementándose en las principales urbes mundiales. En países europeos la delincuencia menor y los comportamientos antisociales han aumentado velozmente, al tiempo que la incidencia de los delitos mayores se ha abordado con cierto éxito en su control. En parte, a causa del empleo de acciones modernas para mantener el orden social y asegurar acciones justas en el ámbito penal. Asimismo, estas medidas se acompañaron de interesantes gestiones de cooperación internacional. Es en el continente asiático donde se evidenció la reducción de la delincuencia en general entre las décadas del setenta y noventa, cuando existía un registro de aumento notable de la delincuencia asociada a la propiedad privada, los actos delictivos de bandas organizadas y el tráfico de estupefacientes en urbes de más de cien mil pobladores (Vanderschueren y Lunecke, 2004).

En el ámbito latinoamericano se puede observar que los delincuentes juveniles constituyen un gran problema aún irresuelto, ya que involucra un considerable aumento en el gasto social para cualquier país, siempre que genere costos relacionados a los servicios de carácter público como los de la sanidad mental, lo judicial y la educación especial. Por lo común, los delincuentes juveniles permanecen en los centros de salud tanto mental como de justicia hasta que son adultos. Se calcula que aproximadamente cada año alguien pierde la vida a causa de arma de fuego entre los 73 mil y 90 mil personas en Latinoamérica (OMS, 2002), esto constituye el triple de la media mundial (UNODC, 2008).

Perú enfrenta, desde hace mucho tiempo, una problemática compleja que combina las dificultades económicas con las lacras sociales. Situación que impacta con mayor agresividad a los sectores más indefensos de la sociedad peruana. En particular a las mujeres, sobre todo madres y niños. Esta coyuntura está acompañada de un aumento poblacional vertiginoso y caótico que precariza los servicios básicos de salud y educación, así como las posibilidades de empleo para la nueva juventud, que se ve desarticulada y sin horizontes optimistas 
de expectativa. Por ello podemos ver que el costo de vida aumenta mientras que el poder adquisitivo baja. Esto acarrea que el desempleo y subempleo se dispare a índices elevadísimos y preocupantes, que la familia se desintegre, que haya más menores abandonados en las calles, que la infancia se postergue para caer en la explotación infantil, que precisamente tanto las mujeres y menores se vean expuestos a condiciones de peligro, explotación y miseria más que antes. No es de extrañarse, entonces, la proliferación de "pandillas juveniles", "barras bravas" y "pirañitas". Sus actos delictivos van desde las infracciones leves hasta delitos mayores que implican carcelería (Vacchelli, 2001). Pasaron los años y la situación es más agravante puesto que la delincuencia es el principal problema del país, entre 2013 y setiembre de 2018, el $40,4 \%$ de la población considera que este problema social debe ser urgentemente atendida (Ministerio del Interior, 2018). El último lustro, la delincuencia juvenil (de 12 a 23 años) ha ido en un incremento sostenido en nada menos que $80 \%$, llegando a extremos de pasar de diez detenciones al día a diez detenciones por hora (Rojas, 2014).

Es una regla casi general que la población juvenil que forma parte de estos grupos delictivos estén en condiciones de clamorosa precariedad educativa, tengan pocas expectativas laborales o profesionales y que se les complique el disfrute de su tiempo libre en esparcimiento sano o la práctica de algún deporte. Esta carencia es debida a su baja condición económica y pobreza extrema (Poblete, 2014).

Los jóvenes son cada vez más violentos y agresivos, por diversos factores, entre ellos los problemas en el hogar disfuncional. Así lo manifiesta Arias (2013) cuando afirma que los conflictos familiares y la separación de los padres pueden acarrear serios problemas durante la adolescencia. Otro elemento para la adopción de la violencia es la paternidad mal entendida, donde se es o muy blando o demasiado rígido, ambos extremos solo originan muchachos en rebeldía constante y disociación social. Los padres deberían comportarse de manera más asertiva y atenta cuando detecten las primeras señales de conductas agresivas o violentas. Por ejemplo, cuando sus hijos no regresen a casa a dormir, huyan de los hogares, se inicien en drogas, sean violentos con animales, con otros compañeros de colegio o barrio, o ya comiencen con la delincuencia como robar o hacer actos vandálicos. Sin embargo, no solo la mala actuación paterna, sino también se presenta la indefensión absoluta de los menores. Jóvenes que han sido abandonados por sus familiares y que incluso el Estado no se ha hecho cargo de sus vidas. Por todo ello, es importante que las autoridades locales y gubernamentales brinden atención oportuna en los casos de agresiones física, sicológica o sexual dentro de los hogares, ya que es en estos ambientes donde germinan los futuros delincuentes (Rojas, 2014).

En este artículo se pretende detectar los principales factores e indicadores que provocan desarrollar dicha ocupación, con el propósito de brindar información a las instituciones respectivas para que tomen las medidas preventivas en aras de la tranquilidad ciudadana. Cabe precisar que son importantes algunos elementos teóricos que permitan fundamentar. 
Factores de la delincuencia juvenil en el Perú desde el enfoque preventivo

\section{Enfoque de la prevención situacional}

El aumento de la delincuencia masiva ha generado otras consecuencias. La primera es el auge de la prevención situacional que se inscribe en la lógica de la disuasión y emerge como una solución privilegiada en varias ciudades. Consiste en modificar el entorno criminógeno para obstaculizar el trabajo del delincuente y disminuir su ganancia, pero sin apuntar, como en la prevención social, a cambiar a los potenciales delincuentes. En los ámbitos urbanos las medidas situacionales se han verificado útiles, aunque a veces solo desplazan la delincuencia. Varias teorías han sustentado este enfoque como "ventana rota” o "teoría de la acción rutinaria", sin embargo, recientemente la acción situacional de Wikström y Treiber (2016) reubicó este enfoque en contextos sociales e históricos más amplios.

La teoría del control social como fundamento de las políticas de seguridad, inspirada sobre todo en las formulaciones de Gottfredson e Hirschi (1990), se imponen políticas que disminuyen el énfasis de prevención social hacia adolescentes y jóvenes, para privilegiar aquella dirigida al apoyo familiar, orientado a la primera infancia. Esta teoría minimiza la posibilidad de modificar los comportamientos de adolescentes y adultos que no hubieran adquirido el "autocontrol" desde la infancia, por ende, conduce a aumentar el control policial y el encarcelamiento, limitándose a medidas disuasivas de prevención situacional. Dicha teoría es la que prevalece específicamente en el Perú y sustenta la investigación.

\section{La personalidad de la juventud delincuencial}

Según Defez (2017), la criminalidad es la sumatoria de diversos factores sociales y psicológicos, pero existen prevalencias de cierto patrón conductual que serían los factores de vulnerabilidad ante la violencia. Factores que afectan principalmente en la pubertad y que se consideran a los personales, familiares, colegiales, los sociales y comunitarios. Cuando estos factores están en crisis o faltan, el joven experimenta una falta de proyecto de vida y muchos son incapaces de adaptarse al contexto social donde se desenvuelven. Es por esta falta de sintonía que terminan cayendo en lo delincuencial casi como la única posibilidad de supervivencia en un ambiente hostil y duro. Asimismo, tras la carencia de factores familiares los jóvenes recurren a las drogas y a la delincuencia como forma de vida y sustento. Y cuando esto se da, el joven ya se mimetiza con dicho entorno hostil y se vuelve particularmente violento, ya que la violencia le ha permitido vivir, convivir, sostenerse y hasta escalar en el mundo delincuencial (Uceda, Navarro y Pérez, 2016). Otros indicadores de riesgo como el recurrente abandono del colegio y del hogar; la baja autoestima, el alcoholismo temprano, la desintegración familiar, la incomunicación entre los elementos de la familia, entre los factores más recurrentes. Jiménez (2005) refiere que la principal causa generadora de delincuencia es la familia disfuncional, así como la precariedad económica, el alcohol y la drogadicción. 
A continuación, se presentan algunos rasgos del delincuente como consecuencia de algunos factores y aspectos preventivos.

Reacción social agresiva: relacionado con la no aceptación familiar, agresión en la infancia, exagerada vigilancia infantil, limita el desarrollo de la personalidad del adolescente ocasionando de una forma u otra los problemas familiares, presentándose actos de hostilidad y agresividad en ellos. Alonso y Castellanos (2006) refieren que el padre y la madre deben conservar la firmeza en la disciplina positiva en las correcciones conductuales que podrían darse. De presentar los padres una actitud volátil o poco firme, esta inconsecuencia con las faltas puede confundir al muchacho. La corrección oportuna de las inconductas de los menores debe darse en su momento y con criterio formativo y no agresivo ni lacerante. Asimismo, no es conveniente una actitud demasiado rígida, tampoco es aconsejable caer en la permisividad, ni al festejo de las malas conductas de los menores como si fueran una gracia. Educar con empatía y la transmisión de afectos, principios y valores deben ser premisas para la formación sustentada en la comunicación permanente y el respeto recíproco (Moreno, 2005).

Reacción de huida: debido a la no aceptación de los padres y el maltrato, más recurrente en lo referido a lo agresivo es cuando se manifiestan en el menor sentimientos de minusvalía e indefensión, así como conductas de retraimiento extremo. Al pertenecer a una pandilla, los menores son despreciados y llamados peyorativamente como indeseables. No se acogen en ámbitos juveniles formales, sino que son estigmatizados como peligrosos, delincuentes o simplemente impresentables. Gracia y Musitu (2005) refieren que el comportamiento de los menores rechazados por la madre o el padre está relacionado con una serie de problemas, por ejemplo, ser impulsivos, hiperactivos, permanentemente desobedientes, autodestructivos, descontrolados y, por lo general, de aspecto y comportamiento hostil para con el resto.

Reacción antisocial, trastorno disocial o psicopatía-sociopatía: aquí se ubican los menores que presentan carencia de incorporación social. Jóvenes que permanente protagonizan problemas de socialización suelen no sentirse identificados con principios nobles como la lealtad, ni experimentan sentimiento de culpa alguno. Han tenido una parentalidad por lo general coercitiva. Desde la infancia suelen arrastrar inconductas que han marcado su psicología. Por ello, externalizan estos problemas con comportamientos inhibidos y actitudes de no socialización. Dan la impresión de comportamiento insensible e irritable, aunque acostumbran a ser locuaces y expresar un encantamiento social superficial. Lo frustrante en estos jóvenes está en niveles bajos y su autoestima por el contrario es muy elevada. Las motivaciones que animan el aumento de este trastorno de no aceptación e indefensión de los padres es lo temperamental de la crianza. Menores con una educación demasiado rígida, abusos de carácter físico o sexual, no haber tenido una mínima supervisión o acompañamiento de vida, se agrupan en bandas delincuenciales o presentan una herencia genética en trastornos sicopáticos (Defez, 2017). Al margen de las consecuencias físicas que acarrean de manera directa el maltrato físico 
Factores de la delincuencia juvenil en el Perú desde el enfoque preventivo

o sexual, todas las formas de abuso infantil ocasionan trastornos en la conducta de preocupante relevancia posterior, no solo en el comportamiento, sino en lo emocional y social. Los abusos mencionados conducen a la perpetración de actos delictivos menores como hurto, agresión a animales, riñas o el empleo de algún tipo de armas, y se presentan en hogares de alto nivel social y económico. La educación rígida paterna en vez de corregir o tratar los problemas, adopta un inadecuado comportamiento de encubrimiento.

Reacción de delincuencia de grupo: encontramos a los integrantes de las pandillas juveniles ya que son una proyección decadente de la cultura hegemónica, puesto que reproducen de alguna forma la familia que no tuvieron una alterna de tipo antisocial. Sossa (2010) menciona que uno de problemas más importantes de la sociedad se origina por las marcadas brechas socioeconómicas en el mundo contemporáneo. El incremento demográfico eleva dichas brechas, originando a su vez resentimiento social y una búsqueda desesperada de sobrevivencia. Esta situación extrema hace que devengan en delincuentes, traficantes, prostitutas y otras manifestaciones de anomia social. Así, los actos delictivos más frecuentes son el robo, vandalismo, hostilizaciones, robo de vehículo, alcoholismo, drogadicción y problemas mentales como la sicosis, entendiendo que la violencia es el inicio de la enfermedad sicológica. Gutiérrez y Portillo (2014) mencionan que el ambiente hostil presenta en los menores conductas de inestabilidad en las emociones, cuadros severos de estrés y ansiedad; a su vez, estos suelen ser víctimas de las consecuencias del estrés postraumático que se presenta en la época infantil, adolescencia o pubertad, lo que ocasiona conductas ensimismadas, escasa interrelación interpersonal, bajo aprovechamiento en las escuelas, hipersensibilidad y ansiedad.

La delincuencia juvenil se presenta en personas que aún no son mayores de edad y cuyas edades oscilan entre los 12 a 18 años que por diversas causas de índole familiar, social, socioeconómica, educativa, han afectado de forma negativa en su desarrollo, trayendo como consecuencia la perpetración de actos delictivos que deberán enfrentar en el ámbito judicial. Frías, Díaz y López (2003) remarcan que el comportamiento antisocial es una manifestación de lo que la sicología denomina trastornos del comportamiento y que la ley suele sancionar.

Los motivos que originan la delincuencia juvenil en el Perú son varios y complejos. En el presente trabajo se mencionan siete:

Factores familiares: son aquellas condiciones negativas que se presentan en el entorno del hogar, donde los padres y familiares no contribuyen al desarrollo del joven, sino todo lo contrario; provocando en sus integrantes una serie de consecuencias negativas que derivan a conductas agresivas para con su entorno, incluso contra sí mismo. Torres, Salazar, Reynaldos, Figueroa y Araiza (2011) resaltan que el entorno familiar es el mejor sistema de control y formación tanto moral como ética, ya que es en el hogar donde se remarcan las conductas inadecuadas relacionadas con el crimen y otros actos delictivos. 
Factores personales: se consideran las condiciones individuales que se relacionan con la afectividad ya que el sujeto, al satisfacer sus necesidades básicas, desarrolla aspectos sicológicos positivos en la formación integral de su personalidad. Ferrari (2010) postula que estos factores están conformados por los problemas de tipo mental (idiotismo, estolidez y retraso) que se encuentran en la posibilidad de ser tratados; sin embargo, existen algunas dolencias complejas que requieren de un tratamiento especial como las sicopatologías, las sicosis, las perturbaciones síquicas, entre otras enfermedades muy frecuentes en la juventud que delinque y, que en la mayoría de los casos, tienen una incidencia genética.

Factores institucionales: son las acciones realizadas por organismos o entidades que intervienen en el ámbito juvenil, ya sea de manera informativa, preventiva o de proyección social para contrarrestar la delincuencia perpetrada por la juventud de determinadas zonas. Sin embargo, estas instituciones pueden perder el rumbo si se comportan con celos institucionales que, en vez de priorizar el amparo de los jóvenes, se da más relevancia a aspectos extras que devienen a desamparar a la juventud objeto de sus funciones. Montero, Villalobos y Valverde (2007) llegan a la conclusión de que estos factores son en esencia de carácter estructural, que definen el eje orgánico de las funciones de cada institución para con los jóvenes en situación de riesgo de violencia.

Factores socioeconómicos: se consideran al estado social y económico en un determinado tiempo y espacio que influye en la convivencia pacífica de los jóvenes en sociedad. En el caso de crisis, tanto del país o personal, los muchachos se ven obligados a delinquir. Situación criticable pero que está condicionada a extremas necesidades no cubiertas por los jóvenes infractores. Para González (2015), estos factores se relacionan con la convivencia misma de los menores que marcan y modelan su personalidad, ya que de crecer en un ambiente socioeconómico precario y violento, asimilar el aprendizaje de una conducta delictiva y una inadecuada normalización de la delincuencia y la agresividad en el duro afán de sobrevivencia. Esto se patentiza en los altos niveles de criminalidad en ambientes socioeconómicos bajos.

Factores políticos: son aquellas políticas, planes y determinadas acciones que el gobierno tanto local como nacional propone como alternativa de involucramiento en la problemática juvenil. Los factores políticos contribuirán en crear alternativas de desarrollo tanto para lo físico como para lo sicológico. Apoyo que se consolidará como medidas efectivas que ayuden a la rehabilitación social y su paulatina reincorporación a la vida social. Este factor es el que se refiere directamente a la idea de autoridad que gestiona y ordena lo social. Es a su vez la forma y capacidad que se tiene para enfrentarla, ya que es un fenómeno sociopolítico también (Ahumada y Grandón, 2015).

Factores educativos: se consideran a las medidas, políticas, programas y demás que abordan el propósito de concientización en los centros de estudio sobre la prevención de la violencia. 
Es una tarea que no pretende solo brindar conocimientos o información actualizada, sino causar un impacto significativo en sus conductas para que, desde lo emocional, antes que de lo racional, se encarrilen en la no violencia y se detecten a tiempo las personas que puedan estar más propensas o en peligro que otras. Sanabria y Uribe (2010) han manifestado que el colegio, además del hogar familiar, es el otro gran impulso de socialización en nuestra sociedad. Allí los menores se forman de manera integral, adoptando conductas y actitudes producto no solo de la doctrina impartida en aulas, sino que sobre todo en comportamientos aprendidos en la práctica constante que aseguran la convivencia en paz.

Factores sociales: son aquellos que se relacionan a las condiciones circunstanciales dentro de un espacio social determinado y que explican de alguna forma los comportamientos de la juventud dentro de su comunidad. Asimismo, son las restricciones y requerimientos, tanto de prestigio y ascenso social dentro del ambiente mismo que los jóvenes adquieren para interrelacionarse con sus pares de la manera óptima. Hernández (2015) refiere que son aquellos condicionamientos del entorno o medio que pueden originar cambios en sus miembros, por ejemplo en un ambiente de convulsión social, su juventud también manifiesta un alto grado de violencia y delincuencia.

\section{Medidas de prevención}

Rodríguez (2009) asegura que la forma más idónea de abordar la violencia y delincuencia producida por jóvenes es asegurando una adecuada prevención. Esto beneficiará no solo a la juventud que es potencialmente delincuente, sino también a sus potenciales víctimas, así como a los familiares tanto de víctimas y victimarios que se perjudican con lo delictivo y el crimen. Dentro de los aportes más importantes se encuentra el propuesto por las Naciones Unidas, organismo internacional que propone, incentiva y brinda facilidades para que los países más castigados por la violencia prevengan con actividades directas la delincuencia juvenil. En el caso de la readaptación y rehabilitación con los jóvenes que ya han delinquido y que probablemente lo sigan haciendo, se las redirige a empleos, oficios, estudios o la práctica de deportes, de tal forma que se alejen de las prácticas delictivas. Con esto se asegura su reinserción a la sociedad y evitar una serie de problemas que se agraven desde lo sicológico, salud y penal.

Libreros, Asprilla y Turizo (2015) aseguran que la prevalencia y buena implementación de políticas del Estado que prevengan la delincuencia juvenil serán de mayor impacto si es que son gubernamentales y que se sostengan en el tiempo como enclaves importantes en la lucha contra la delincuencia en su foco juvenil. Tomando en cuenta que el beneficio de la comunidad y calidad de vida de la vecindad en su conjunto mejorarán de manera significativa, ya que la reeducación, control y rehabilitación, así como la prevención se evitará que los futuros delincuentes eviten serlo, para que se transformen en gente de bien, útiles a la sociedad y con un plan de vida no solo largo, sino expectante. De la misma manera, se debe tener en cuenta 
que los diversos sectores de intervención (familiar, escolar y comunitario) deben presentarse de manera coordinada para que se transformen en verdaderas herramientas de socialización, y reduzcan el crimen tanto local como nacional.

\section{Metodología}

La presente investigación se enfocó dentro del paradigma neopositivista, entendiéndolo como el enfoque que determina a la realidad asociado a la investigación cuantitativa, debido a que las hipótesis propuestas se someterán a una contrastación estadística, donde lo matemático asegurará la posibilidad de proyección y extensión de los resultados o hallazgos para otras realidades similares. El tipo de investigación es sustantiva en el sentido que lo expresa Sánchez y Reyes (2015), como aquella que se orienta a contestar las preguntas propuestas en la problemática de investigación y que, para ello, describe el fenómeno investigado, los explica y al relacionar su génesis y causalidades se proyecta a nuevas hipótesis en la generación de conocimiento nuevo y relevante. El diseño de investigación corresponde al no experimental del subtipo de diseño descriptivo explicativo, ya que se describe el fenómeno afectado por la variable de estudio, así como la explicación desde lo teórico sobre los principales factores que la estarían originando. La investigación de tipo descriptiva busca la caracterización del fenómeno puesto en cuestión, o de un sujeto o grupo de sujetos, con el propósito de entender el comportamiento de la variable en un determinado contexto espacial y temporal. De acuerdo con los resultados de la investigación, estos se ubicarían en un nivel medio de profundidad.

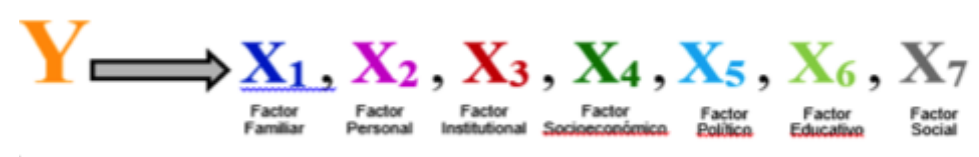

Con relación al método adoptado, se optó por el hipotético-deductivo, entendido como la investigación que se formula posibles respuestas a sus preguntas de investigación y busca contrastarlas con evidencia empírica, sujeta a pruebas estadísticas.

Se inició la investigación con la entrevista a siete expertos o más bien profesionales que trabajaban en el Centro Juvenil de Diagnóstico y Rehabilitación de Lima Maranguita, ello se realizó a través de un grupo focal (focus group). Esta técnica cualitativa es resaltada por Hernández, Fernández y Baptista (2014), quienes remarcaron que con el focus groups se logra interrelacionar a un grupo de especialistas, para que a través de sus intercambios de ideas y opiniones en torno a un tema de delincuencia juvenil.

Al iniciar la investigación no teníamos componentes, dimensiones, indicadores objetivos que respondieran a nuestra realidad en cuanto a delincuencia juvenil, por ello se partió de 
las entrevistas y grupos focales a especialistas, aunado a la teorización pudimos identificar indicadores y factores emergentes que conducen a la delincuencia juvenil; es partir de allí que se construyen los ítems para dar origen al cuestionario.

Otra técnica empleada en la investigación fue la encuesta, a través del cuestionario como instrumento idóneo. Por ello se optó por una escala tipo Likert, la que se aplicó a 93 participantes, todos pertenecientes a pandillas limeñas, adolescentes entre 14 a 17 años de edad de los distritos de San Juan de Lurigancho, Villa el Salvador y Callao, proporcionalmente.

Los instrumentos se sometieron a una validación por contenido a través del juicio de expertos, quienes establecieron la suficiencia de cada instrumento analizando la pertinencia, relevancia, claridad de cada ítem y, en suma, la suficiencia de todo el instrumento, así como de su aplicabilidad. La validez de constructo fue realizada por medio de un análisis tipo factorial. Análisis que determina y ajusta la adecuación de cada ítem en sus respectivas dimensiones (Hair, Anderson, Tatham y Black, 1999). De dicha revisión analítica y factorial se obtuvo que el factor 1 (familiar) representa el 31,463\% de lo variable de los factores que originan la delincuencia juvenil de acuerdo al reporte policiaco de la comisaría consultada; el factor 2 (personal) explicaría el 20,569\% de la variabilidad de los factores; el factor 3 (institucional) representa el 17,326\% de lo variable de los factores; el factor 4 (socioeconómico) explicaría el 9,030\% de la variabilidad de los factores; el factor 5 (político) explicaría el 8,846\% de lo variable de los factores; el factor 6 (educativo) representa el 3,724\% de la variabilidad y, finalmente, el factor 7 (social) significaría la explicación sobre la variabilidad de los factores que darían origen a la delincuencia juvenil de acuerdo con adolescentes de pandillas a un 2,924\%. Al sumar los siete factores se encuentra que explicaría un total de 93,882\% de la variabilidad que provoca la delincuencia juvenil.

La fiabilidad del instrumento se aplicó el Alfa de Cronbach, ya que las escalas de evaluación eran ordinales. La variable Delincuencia juvenil sacó 0,934 de fiabilidad elevada. Lo mismo se aplicó para las siete dimensiones. La primera evidenció una fiabilidad elevada $(0,903)$; la segunda, una fiabilidad aceptable $(0,659)$; la tercera, una fiabilidad buena $(0,748)$; la cuarta, una fiabilidad buena $(0,848)$; la quinta dimensión, una fiabilidad aceptable $(0,692)$; y la sexta, una fiabilidad baja $(0,536)$. Esto último se debería a que las preguntas 54, 55, 56 y 58 están en relación negativa con las demás preguntas. Al variar el sentido, se expresa una fiabilidad buena $(0,778)$. De esta forma, se concluye que el instrumento en general manifiesta alta fiabilidad.

Se vio la necesidad de aplicar la normalidad de los datos para la elección del estadígrafo que se encargará de la prueba de hipótesis; este proceso se realizó con el estadístico KolmogorovSmirnov, ya que la muestra de estudio fue mayor a 50 participantes, después del análisis se afirmó que los datos presentan una distribución no normal. Por ello que se eligió un estadístico no paramétrico, para este caso la prueba de regresión logística para identificar la predominancia de los factores e indicadores. 


\section{Resultados}

Tabla 1. Regresión logística de los factores de la delincuencia juvenil.

\begin{tabular}{|c|c|c|c|c|c|c|}
\hline \multirow{2}{*}{ Factor } & \multirow{2}{*}{ B } & \multirow{2}{*}{$\begin{array}{c}\text { Error } \\
\text { estándar }\end{array}$} & \multirow{2}{*}{ Sig. } & \multirow{2}{*}{$\operatorname{Exp}(B)$} & \multicolumn{2}{|c|}{ 95\% C.I. para EXP(B) } \\
\hline & & & & & Inferior & Superior \\
\hline Factor familiar &,- 048 &, 532 & ,928 & ,953 & ,336 & 2,705 \\
\hline Factor personal &,- 260 &, 540 & ,631 & ,771 &, 267 & 2,224 \\
\hline Factor institucional &,- 321 & ,432 & ,458 & ,725 & ,311 & 1,693 \\
\hline Factor socioeconómico &, 129 & ,486 &, 791 & 1,137 & ,438 & 2,951 \\
\hline Factor Político & ,405 & ,418 &, 333 & 1,499 & ,660 & 3,401 \\
\hline Factor Educativo &,- 780 &, 566 &, 169 & , 458 &, 151 & 1,391 \\
\hline Factor Social & ,856 &, 548 &, 118 & 2,353 & ,804 & 6,886 \\
\hline
\end{tabular}

Fuente: base de datos.

Debido a que la significancia (p. valor o Sig.) es mayor al valor $\alpha$ (margen de error al ,005) en todos los factores, no se rechaza la hipótesis nula. Por consiguiente, no se presentan diferencias significativas entre un factor y otro que provocan la delincuencia juvenil en el Perú. Sin embargo, al dar respuesta al objetivo general de la investigación según resultados se afirma que el factor predominante que origina la delincuencia juvenil en el Perú es el factor social $(\mathrm{B}=0,856)$, presenta mayor coeficiente. Así mismo, este factor presenta un odds ratio $(\operatorname{Exp}(B))=2,353$, significando que es un factor de riesgo, que si las autoridades, nacionales, regionales y locales no trabajan estableciendo planes o proyectos preventivos la situación irá en crecimiento, es fundamental que se trabaje involucrando a los jóvenes en reuniones y atención a las necesidades de la vecindad, la creación de complejos recreacionales que inciten al deporte, talleres de música, danza y otros, es necesario articular todas las entidades públicas y privadas en pro de una contribución a la formación y sensibilización a la población.

Tabla 2. Regresión logística de los indicadores del factor familiar de la delincuencia juvenil.

\begin{tabular}{lcccccc}
\hline \multicolumn{1}{c}{ Indicador } & B & $\begin{array}{c}\text { Error } \\
\text { estándar }\end{array}$ & Sig. & $\operatorname{Exp(B)}$ & \multicolumn{2}{c}{$\mathbf{9 5 \% \text { C.I. para EXP(B) }}$} \\
\cline { 6 - 7 } & & & Inferior & Superior \\
\hline $\begin{array}{l}\text { Violencia en la familia } \\
\text { debido a la falta de valores } \\
\text { de sus miembros }\end{array}$ & 0,040 & 0,415 & 0,922 & 1,041 & 0,462 & 2,348 \\
$\begin{array}{l}\text { Baja cohesión familiar } \\
\begin{array}{l}\text { Falta del apoyo familiar hacia } \\
\text { los jóvenes en riesgo }\end{array}\end{array}$ & 0,020 & 0,470 & 0,966 & 1,020 & 0,406 & 2,566 \\
\hline
\end{tabular}

Fuente: base de datos. 
Factores de la delincuencia juvenil en el Perú desde el enfoque preventivo

Debido a que la significancia (p. valor o Sig.) es mayor al valor $\alpha$ (margen de error al ,005) en todos los indicadores, no se rechaza la hipótesis nula. Por consiguiente no se presentan diferencias significativas entre los indicadores del factor familiar, no obstante para dar respuesta al objetivo específico 1; el indicador que origina la delincuencia juvenil es la falta del apoyo familiar hacia los jóvenes en riesgo $(B=0,384)$, ya que evidencia mayor coeficiente dentro del factor familiar, este indicador presenta un odds ratio $(\operatorname{Exp}(B))=1,469$, que significa un indicador de riesgo, por consiguiente es fundamental la prevención en las familias, específicamente la comunicación entre padres e hijos, el tiempo que los padres dedican en la atención a sus hijos.

Tabla 3. Regresión logística de los indicadores del factor personal de la delincuencia juvenil.

\begin{tabular}{|c|c|c|c|c|c|c|}
\hline \multirow{2}{*}{ Indicador } & \multirow{2}{*}{ B } & \multirow{2}{*}{$\begin{array}{l}\text { Error } \\
\text { estándar }\end{array}$} & \multirow{2}{*}{ Sig. } & \multirow{2}{*}{$\operatorname{Exp}(B)$} & \multicolumn{2}{|c|}{ 95\% C.I. para EXP(B) } \\
\hline & & & & & Inferior & Superior \\
\hline $\begin{array}{l}\text { Falta de formación de la } \\
\text { personalidad en jóvenes }\end{array}$ & $-0,781$ & 0,450 & 0,082 & 0,458 & 0,190 & 1,105 \\
\hline $\begin{array}{l}\text { Baja autoestima de los } \\
\text { jóvenes }\end{array}$ & 1,147 & 0,480 & 0,017 & 3,148 & 1,229 & 8,063 \\
\hline
\end{tabular}

Fuente: base de datos.

Debido a que la significancia (p. valor o Sig.) es menor al valor $\alpha$ (margen de error al ,005) en uno de los indicadores del factor, se acepta la hipótesis planteada. Por consiguiente, se presentan diferencias significativas entre los indicadores del factor personal. Como respuesta al objetivo específico 2, el indicador la baja autoestima de los jóvenes $(B=1,147)$ manifiesta un valor mayor de coeficiente y por ende provoca la delincuencia juvenil, este indicador presenta un odds ratio $(\operatorname{Exp}(B))=3,148$, que significa un indicador de riesgo, por ello debemos estar atentos en las actitudes emocionales y la identidad, la aceptación y amor que cada uno de los jóvenes se tiene.

Tabla 4. Regresión logística de los indicadores del factor institucional de la delincuencia juvenil.

\begin{tabular}{lcccccc}
\hline \multicolumn{1}{c}{ Factor } & B & $\begin{array}{c}\text { Error } \\
\text { estándar }\end{array}$ & Sig. & Exp(B) & \multicolumn{2}{c}{$\mathbf{9 5 \% \text { C.I. para EXP(B) }}$} \\
\cline { 5 - 7 } & $-1,092$ & 0,671 & 0,104 & 0,336 & 0,090 & 1,249 \\
\hline Celos institucionales & 0,106 & 0,533 & 0,842 & 1,112 & 0,391 & 3,164 \\
$\begin{array}{l}\text { Desinformación de actos ilícitos } \\
\begin{array}{l}\text { Falta de prácticas continuas de } \\
\text { Prevención }\end{array}\end{array}$ & $-2,515$ & 1,040 & 0,016 & 0,081 & 0,011 & 0,621 \\
$\begin{array}{l}\text { Falta de confianza de los jóvenes } \\
\text { en riesgo hacia los policías }\end{array}$ & 2,377 & 1,030 & 0,021 & 10,776 & 1,432 & 81,081 \\
\hline
\end{tabular}

Fuente: base de datos. 
Debido a que la significancia (p. valor o Sig.) es menor al valor $\alpha$ (margen de error al ,005) en dos de los indicadores del factor, se rechaza la hipótesis nula. Por consiguiente, se presentan diferencias significativas en los indicadores del factor institucional que provoca la delincuencia juvenil. En respuesta al objetivo específico 3, el indicador que predomina es la falta de prácticas continuas de prevención $(B=-2,515)$ ya que presenta mayor coeficiente y por ende provoca la delincuencia juvenil, esto en el factor instituciona; este indicador presenta un odds ratio $(\operatorname{Exp}(B))=0,081$, significando que es un indicador de protección, que quiere decir que si se establece acciones preventivas desde las instituciones públicas y privadas, de manera constante, se disminuiría la delincuencia juvenil.

Tabla 5. Regresión logística de los indicadores del factor socioeconómico de la delincuencia juvenil.

\begin{tabular}{|c|c|c|c|c|c|c|}
\hline \multirow{2}{*}{ Indicador } & \multirow{2}{*}{ B } & \multirow{2}{*}{$\begin{array}{c}\text { Error } \\
\text { estándar }\end{array}$} & \multirow{2}{*}{ Sig. } & \multirow{2}{*}{$\operatorname{Exp}(B)$} & \multicolumn{2}{|c|}{ 95\% C.I. para EXP(B) } \\
\hline & & & & & Inferior & Superior \\
\hline $\begin{array}{l}\text { Captación de jóvenes por parte de } \\
\text { los mercenarios de las drogas }\end{array}$ & $-1,286$ & 0,380 & 0,001 & 0,276 & 0,131 & 0,583 \\
\hline $\begin{array}{l}\text { Deficiente labor de los medios de } \\
\text { comunicación }\end{array}$ & 1,034 & 0,476 & 0,030 & 2,812 & 1,107 & 7,143 \\
\hline $\begin{array}{l}\text { Influencia negativa de jóvenes que } \\
\text { pertenecen a bandas violentas }\end{array}$ & 1,502 & 0,443 & 0,001 & 4,490 & 1,885 & 10,692 \\
\hline $\begin{array}{l}\text { Influencia del alcoholismo en } \\
\text { jóvenes de la zona }\end{array}$ & $-1,136$ & 0,452 & 0,012 & 0,321 & 0,132 & 0,779 \\
\hline Inaccesibilidad del terreno & 0,033 & 0,438 & 0,941 & 1,033 & 0,438 & 2,436 \\
\hline
\end{tabular}

Fuente: base de datos.

Debido a que la significancia (p. valor o Sig.) es menor al valor $\alpha$ (margen de error al ,005) en cuatro de los indicadores del factor, se rechaza la hipótesis nula. Por consiguiente, existen diferencias en los indicadores del factor socioeconómico que provocan a la delincuencia juvenil, en respuesta al objetivo específico 4 el indicador influencia negativa de jóvenes que pertenecen a bandas violentas $(B=1,502)$ presenta mayor coeficiente $y$, por tanto, provoca la delincuencia juvenil. De la misma forma, este indicador del factor socioeconómico presenta un odds ratio $(\operatorname{Exp}(B))=4,490$, que significa un indicador de riesgo, los jóvenes se encuentran vulnerables, ya que por falta de dinero inician a delinquir por las órdenes o influencias de amistades negativas. 
Factores de la delincuencia juvenil en el Perú desde el enfoque preventivo

Tabla 6. Regresión logística de los indicadores del factor político de la delincuencia juvenil.

\begin{tabular}{lcccccc}
\hline \multicolumn{1}{c}{ Indicador } & B & $\begin{array}{c}\text { Error } \\
\text { estándar }\end{array}$ & Sig. & $\operatorname{Exp}(\mathbf{B})$ & \multicolumn{2}{c}{$\mathbf{9 5 \% \text { C.I. para EXP(B) }}$} \\
\cline { 6 - 7 } & 0,509 & 0,417 & 0,222 & 1,664 & 0,735 & 3,764 \\
\hline $\begin{array}{l}\text { Falta de presencia del } \\
\text { estado en la zona }\end{array}$ & $-0,681$ & 0,493 & 0,167 & 0,506 & 0,193 & 1,330 \\
$\begin{array}{l}\text { Perdida de la instrucción } \\
\text { pre militar en los colegios }\end{array}$ & & & & & & Superior \\
$\begin{array}{l}\text { Código de niños y } \\
\text { adolescentes por parte de } \\
\text { los jóvenes en riesgo }\end{array}$ & $-0,196$ & 0,345 & 0,570 & 0,822 & 0,418 & 1,617 \\
\hline
\end{tabular}

Fuente: base de datos.

Debido a que la significancia (p. valor o Sig.) es mayor al valor $\alpha$ (margen de error al ,005) en todos los indicadores del factor, no se rechaza la hipótesis nula. Por consiguiente, no se presentan diferencias significativas en los indicadores del factor político. En respuesta al objetivo específico 5, el indicador perdido de la instrucción pre-militar en los colegios ( $\mathrm{B}=$ $-0,681$ ) presenta mayor coeficiente y por ende provoca la delincuencia juvenil, este indicador del factor político presenta un odds ratio $(\operatorname{Exp}(B))=0,506$, significando que es un indicador de protección, como hechos preventivos si los jóvenes tuvieran instrucción pre militar centrada en la disciplina y respeto se evitaría la delincuencia juvenil.

Tabla 7. Regresión logística de los indicadores del factor educativo de la delincuencia juvenil.

\begin{tabular}{|c|c|c|c|c|c|c|}
\hline \multirow{2}{*}{ Indicador } & \multirow{2}{*}{ B } & \multirow{2}{*}{$\begin{array}{l}\text { Error } \\
\text { estándar }\end{array}$} & \multirow{2}{*}{ Sig. } & \multirow{2}{*}{$\operatorname{Exp}(B)$} & \multicolumn{2}{|c|}{ 95\% C.I. para EXP(B) } \\
\hline & & & & & Inferior & Superior \\
\hline $\begin{array}{l}\text { Escaza concientización en los } \\
\text { colegios }\end{array}$ & 0,875 & 0,465 & 0,060 & 2,398 & 0,964 & 5,965 \\
\hline $\begin{array}{l}\text { Falta de cultura que es } \\
\text { recurrente de actos irregulares } \\
\text { en la zona }\end{array}$ & $-0,292$ & 0,448 & 0,514 & 0,746 & 0,310 & 1,798 \\
\hline Uso indebido de la tecnología & $-0,684$ & 0,408 & 0,094 & 0,504 & 0,227 & 1,122 \\
\hline
\end{tabular}

Fuente: base de datos.

Debido a que la significancia (p. valor o Sig.) es mayor al valor $\alpha$ (margen de error al ,005) en todos los indicadores del factor, no se rechaza la hipótesis nula. Por tanto, no se presentan diferencias significativas entre los indicadores del factor educativo, en respuesta al objetivo de investigación 6, el indicador la escaza concientización en los colegios $(\mathrm{B}=0,875)$ presenta mayor coeficiente y, por ende, provoca la delincuencia juvenil, además presenta un odds ratio $(\operatorname{Exp} B=2,398)$ que significa que es un indicador de riesgo; si en las instituciones educativas no se trabaja de manera coordinada con otras instituciones en la atención de estudiantes con comportamientos inadecuados, de seguro tendremos mayor delincuencia juvenil. 
Tabla 8. Regresión logística de los indicadores del factor social de la delincuencia juvenil según la policía de Villa el Salvador - 2016.

\begin{tabular}{|c|c|c|c|c|c|c|}
\hline \multirow{2}{*}{ Indicador } & \multirow{2}{*}{ B } & \multirow{2}{*}{$\begin{array}{c}\text { Error } \\
\text { estándar }\end{array}$} & \multirow{2}{*}{ Sig. } & \multirow{2}{*}{$\operatorname{Exp}(B)$} & \multicolumn{2}{|c|}{ 95\% C.I. para $\operatorname{EXP(B)}$} \\
\hline & & & & & Inferior & Superior \\
\hline $\begin{array}{l}\text { Falta de participación de jóvenes } \\
\text { en las juntas vecinales }\end{array}$ & 0,722 & 0,313 & 0,021 & 2,059 & 1,115 & 3,802 \\
\hline $\begin{array}{l}\text { Complejos de nuestra } \\
\text { comunidad }\end{array}$ & $-0,496$ & 0,323 & 0,125 & 0,609 & 0,324 & 1,147 \\
\hline $\begin{array}{l}\text { Escasa sensibilización en la } \\
\text { población }\end{array}$ & $-0,420$ & 0,358 & 0,240 & 0,657 & 0,326 & 1,325 \\
\hline $\begin{array}{l}\text { Falta de talleres brindados por } \\
\text { la empresa privada para jóvenes } \\
\text { en riesgo }\end{array}$ & $-0,190$ & 0,325 & 0,560 & 0,827 & 0,437 & 1,565 \\
\hline
\end{tabular}

Fuente: base de datos.

Debido a que la significancia (p. valor o Sig.) es menor al valor $\alpha$ (margen de error al ,005) en uno de los indicadores del factor, se rechaza la hipótesis nula. Por consiguiente, se presentan diferencias significativas en los indicadores del factor social. En respuesta al objetivo específico 7, falta de participación de jóvenes en las juntas vecinales $(B=0,722)$ presenta mayor coeficiente y por ende provoca la delincuencia juvenil; este indicador del factor social presenta un odds ratio $(\operatorname{Exp}(B))=2,059$, que significa un indicador de riesgo que si no enseñamos a los jóvenes a trabajar con autonomía no tendremos jóvenes que participen en múltiples actividades formativos que ayude en la prevención de la delincuencia.

\section{Discusión de resultados}

A partir del resultado inferencial general se puede deducir el predominio del factor social con un $\mathrm{B}=, 856$, presenta un coeficiente mayor explicando que provocaría con mayor significancia la delincuencia juvenil. Además, este factor marca un odds ratio $(\operatorname{Exp}(B))=2,353$, constituyendo un factor de riesgo. Podemos afirmar que si las autoridades, instituciones públicas y privadas no se preocupan por identificar, diagnosticar y hacer seguimiento con acciones de fortalecimiento de capacidades de los jóvenes, la delincuencia en nuestra sociedad se incrementará. Al contrastar los resultados obtenidos se observa diferencia significativa. Esto entra en consonancia con lo encontrado por Pichardo (2014), con relación a los jóvenes que se encuentran privados de su libertad en la cárcel de mujeres, concluyó que el factor ambiental fue el predominante que condujo a la delincuencia. Por tanto, este ambiente social donde muchos jóvenes pasan mayor tiempo, ya sea con malos amigos, vecinos, compañeros de trabajo son las que conducen a la delincuencia es por ello que las autoridades deben establecer o insertar múltiples actividades educativas en distintos sectores de la ciudad como académicas y de entretenimiento, para que jóvenes se incorporen y se alejen de las drogas, licor y delincuencia, en la investigación se 
Factores de la delincuencia juvenil en el Perú desde el enfoque preventivo

considera importante involucrar a los jóvenes en la participación activa de las juntas vecinales para adquirir habilidades de responsabilidad social.

Dentro del factor familiar es el apoyo familiar el indicador predominante con un valor de B $=$,384. Al presentar el coeficiente mayor y por tanto ser el elemento más relevante en la causa de la delincuencia juvenil. El apoyo familiar marca un odds ratio $(\operatorname{Exp}(\mathrm{B})=1,469$, que significa un indicador de riesgo. Por tanto, si se descuida el apoyo familiar o hay ausencia de esta, conllevará a un lamentable aumento de la delincuencia juvenil. Este resultado entra en concordancia con lo hallado por Sánchez (2013), quien investigó el apego familiar con relación a la función educadora y encontró que es muy relevante, así como el nivel intelectual y cultural que se exprese en el ámbito familiar. Ya que cuando en el entorno familiar no hay una agenda cultural ni interés por lo educativo o lo manifiesta de manera precaria, el resultado educativo de los hijos de ese contexto es tan o igual de bajo que su entorno. Por ello, cuando un muchacho se sitúa en una zona de riesgo, necesita mucho más del apoyo familiar para salir de su problemática y volverse a encarrilar a un desarrollo óptimo; si el joven se encuentra en problemas y lo que recibe de la familia es violencia, lo exponen a acudir a otras personas que se encuentran involucradas en actividades delictivas.

Con relación al factor personal, se observa que el indicador baja autoestima resulta el predominante con un valor de $\mathrm{B}=1,147$, ya que manifiesta un coeficiente mayor y por tanto, provoca la delincuencia juvenil. Asimismo, este indicador marca un odds ratio $(\operatorname{Exp}(\mathrm{B}))=$ 3,148 , que significa un indicador de riesgo. Por tanto, si no se desarrolla el valor, el respeto e identidad propia de los adolescentes, se estaría incrementando la delincuencia juvenil. Este resultado entra en contraste con lo hallado por Zamudio (2015). La investigación estimó la extroversión medida con el EPQ-R de muchachos de 16 a 20 años que habían cometido delitos graves (de robo, posesión ilegal de armas hasta homicidio y tráfico de drogas) del Centro Juvenil de Diagnóstico y Rehabilitación de Lima. Esta no significancia hallada se explicaría en relación de que no necesariamente un joven extrovertido ocasiona delitos, sino que siendo o no extrovertidos presentan desordenes siquiátricos y sí están expuestos a la perpetración de delitos y crímenes de acuerdo al ambiente y contexto que se los facilite. Los jóvenes pueden ser introvertidos o extrovertidos, sin embargo es fundamental que tengan autoestima bien establecida, que permita afrontar situaciones de riesgo, ya que jóvenes con dicha característica reaccionan mejor ante la adversidad, además tener autoestima alta nos permite reconocer nuestros errores y mejorar progresivamente. Si los jóvenes tienen autoestima baja tienen un concepto negativo de sí mismo, piensan que no son merecedores de nada y ellos los conduce a cumplir imposiciones y órdenes delictivas.

En el factor institucional se observa la predominancia del indicador carencia de prácticas de prevención con un valor de $\mathrm{B}=-2,515$, ya que demuestra un coeficiente mayor $\mathrm{y}$, por tanto, provoca la delincuencia juvenil. Este indicador marca un odds ratio $(\operatorname{Exp}(\mathrm{B}))=0,081$, cuya 
interpretación refiere que se trata de un indicador de protección, de la que podemos afirmar que si se trabajan acciones preventivas desde las instituciones involucradas en la lucha contra la delincuencia juvenil, esta disminuirá. Este hallazgo entra convergencia con lo hallado por Salamea (2014). Quien demuestra en su investigación que la delincuencia juvenil se ha exteriorizado, al presentar una perspectiva de sanción que no cuenta con una alternativa de rehabilitación ni prevención en el Ecuador. Hay múltiples instituciones. Mientras haya más sanciones drásticas aparentemente la delincuencia incrementa, se hacen necesarios programas que atiendan a niños, jóvenes y las familias centradas en atención médica: salud mental, psicológica integración y socialización. Así mismo, las instituciones son las que deben acercarse a los jóvenes para insertarles confianza como elemento fundamental y participar en actividades de prevención.

Con relación al factor socioeconómico se observa que el indicador pertenencia a bandas violentas es el predominante negativo con un valor de $\mathrm{B}=1,502$; ya que muestra el coeficiente mayor y, por tanto, provoca la delincuencia juvenil. Este indicador marca un odds ratio $(\operatorname{Exp}(\mathrm{B}))$ $=4,490$, que significa un indicador de riesgo. En las calles los jóvenes están expuestos al alcoholismo, a la captación por mercenarios de las drogas y luego la pertenencia a bandas violentas, esto debido a la carencia de dinero y pretender cubrir sus necesidades, mientras no se haga nada por ello los jóvenes seguirán en peligro. Esto entra en concordancia complementaria con lo hallado por Rojas (2013), quien señala que en varias ocasiones los estudiantes que son parte de grandes unidades escolares, suelen ejercer un bullying colegial, cuando están en grupo. Estos adolescentes suelen pertenecer a pandillas, por lo que su comportamiento en las escuelas es agresivo e intimidante con el resto de los alumnos. El ejercicio de la violencia que practican es peligroso, ya que además de agresiones físicas dejan secuelas sicológicas en sus víctimas. La formación de grupos es importante ya que desarrollamos habilidades cooperativas y colaborativas con propósitos positivos, entonces desde los hogares y los colegios es importante enseñar a los niños y jóvenes a ser responsables y disciplinados, para que cuando tengan necesidades trabajen y no caigan en manos de grupos delictivos.

El factor político presenta como indicador predominante a la instrucción pre-militar en las escuelas con un valor de $\mathrm{B}=-0,681$. Este factor evidencia un coeficiente mayor y por lo tanto, provoca la delincuencia juvenil. Además, marca un odds ratio $(\operatorname{Exp}(\mathrm{B}))=0,506$, significando que es un indicador de protección. Esto implica remarcar el hecho de que varios autores, incluso personas entrevistadas sobre el tema de la delincuencia juvenil, reconocen que cuando se eliminó la instrucción premilitar en las escuelas secundarias, la delincuencia recrudeció. En este punto, se infiere que lo obtenido es una consecuencia de la baja gestión del gobierno. Estos resultados se refuerzan con lo hallado por Salazar (2014), quien encuentra responsabilidad en el Estado del Perú, ya que sus lineamientos no están correctamente estructurados para hacer frente a la delincuencia juvenil. Estamos seguros de que el servicio militar obligatorio ayudaría a prevenir la delincuencia debido a que en las instituciones militares regulan el comportamiento centrado en la disciplina, honestidad, honradez y responsabilidad. 
El factor educativo presenta como indicador predominante a la escasa concientización en los colegios con un valor de $\mathrm{B}=, 875$. Este indicador demuestra un coeficiente mayor y, por tanto, provoca la delincuencia juvenil. Este indicador presenta un odds ratio $(\operatorname{Exp}(\mathrm{B}))=2,398$, que significa un indicador de riesgo. Se demuestra que desde las autoridades del Estado, de los colegios y hasta los padres, no somos conscientes de qué es lo mejor para los jóvenes en formación. En las instituciones educativas se da más realce al avance cognitivo dejando de lado el tema conductual, la práctica de valores que debería ser el primer orden de atención, porque solo así se lograría mejores aprendizajes. Este hallazgo entra en abierto contraste con lo hallado a través de una posición opuesta, y constituiría un aporte de solución a dicha problemática. Sánchez (2013) asevera que resultaría conveniente que trabajen conjuntamente la familia y el centro educativo en proyectos relacionados a la prevención de la violencia que involucre a su vez a los padres, profesores y demás miembros de la comunidad educativa. Asimismo, en importante remarcar que, mediante estas actividades colegiales, se podría asegurar una mejor comunicación entre profesor y alumno.Y, por tanto, se lograrían mejores resultados en su formación integral.

El factor social presenta el indicador de falta de participación de jóvenes en las juntas vecinales como el indicador predominante con un valor de $\mathrm{B}=0,722$. Este indicador demuestra un coeficiente mayor, y por tanto, provoca la delincuencia juvenil con un odds ratio $(\operatorname{Exp}(\mathrm{B}))=$ 2.059, que significa un indicador de riesgo. Este resultado entra en contraste con lo hallado por Lara (2015), quien argumenta que las acciones realizadas por la policía nacional y todos los elementos relacionados con el freno de la delincuencia juvenil están en relación directa con el aprecio de la comunidad. Esto significa que los pobladores presentan un fuerte sentido de identificación y se involucran en distintos organizaciones e instituciones creadas con el propósito de la erradicación de problemas sociales como la delincuencia juvenil. La participación en grupos sociales, juntas vecinales o voluntariado con objetivos a favor de la sociedad, contribuye en la formación de la persona y con ello evitaríamos que algunos jóvenes se inserten en la delincuencia.

\section{Conclusiones}

El componente que conduce a la delincuencia juvenil en el Perú es el factor social, producto de las circunstancias, lugares que habitan y amistades que los rodean, sumados a ello el olvido y la falta de atención de las autoridades; en el entorno familiar, la falta del apoyo hacia los jóvenes por ausencia de los padres es un hecho que conduce a conductas inadecuadas; en el factor económico, la falta de prácticas continuas de prevención es la que involucra al adolescente en acciones delictivas, ya que las remuneraciones son mal utilizadas sin intención de ahorro, es por ello que cuando no tienen dinero optan por conductas inapropiadas. Por último, el indicador predominante dentro del factor educativo es la escasa concientización en los colegios debido a que los programas de tutoría en las IE no tiene el personal suficiente, ni idóneo para la atención personalizada de los adolescentes. 


\section{Referencias}

Ahumada, H. y Grandón, P. (2015). Significados de la reinserción social en funcionarios de un centro de cumplimiento penitenciario. Psicoperspectivas, 14(2), 84-95.

Alonso, J. M. y Castellanos, J. L. (2006). Por un enfoque integral de la violencia familiar. Psychosocial Intervention, 15(3), 253-274.

Arias, W. (2013). Agresión y violencia en la adolescencia: la importancia de la familia. Unifé, 21(1), 23-34.

Defez, C. (2017). Delincuencia Juvenil. Revista de Pensamiento Penal, 1-55

Ferrari, A. (2010). Factores que influyen en la delincuencia juvenil. Recuperado de https:// arnaldoferrari.wordpress.com/2010/07/01/factores-que-influyen-en-la-delincuenciajuvenil/.

Frías, M., Díaz, S. y López, A. (2003). Predictores de la conducta antisocial juvenil: un modelo ecológico. Estudios de Psicología. Revista de la Universidad Sonora, 8(1), 15-24.

González, E. (2015) Factores de contexto socioeconómicos y educativos en estudiantes de nivel superior, sugerencia para una realidad actual. Interamerican Journal of Psychology, 49(3), 398-412.

Gottfredson, M. R. \& Hirschi, T. (1990). A General Theory of Crime Stanford. CA: Stanford University Press.

Gracia, E., Lila, M. y Musitu, G. (2005). Rechazo parental y ajuste psicológico y social de los hijos. Salud Mental, 28(2), 73-81.

Gutiérrez, J. y Portillo, C. (2014) La violencia delincuencial asociada a la salud mental en la población salvadoreña. Revista de Psicología, 32(1), 3-37.

Hair, J. F., Anderson, R. E., Tatham, R. L. \& Black, W. C. (1999). Multivariate data analysis. Upper Saddle River, NJ: Prentice-Hall International.

Hernández, R., Fernández, C. y Baptista, M. (2014). Metodología de la investigación. México D.F., México: McGraw-Hill/Interamericana Editores S. A.

Hernández, Z. (2015). Factores sociales relacionados a la dependencia funcional de los adultos mayores. Centro de salud 9 de enero. Chachapoyas-2015 (tesis de licenciatura). Universidad Nacional Toribio Rodríguez de Mendoza de Amazonas Chachapoyas, Triunfo, Perú.

Jiménez, R. (2005). La delincuencia juvenil: fenómeno de la sociedad actual. Papeles de población, 11(43), 215-261. 
Factores de la delincuencia juvenil en el Perú desde el enfoque preventivo

Lara, J. (2015). La inseguridad ciudadana y la percepción de inseguridad en el distrito de Huaura período: 2011-2015 (tesis de maestría). Universidad Católica Sedes Sapientiae, Lima, Perú.

Libreros, D., Asprilla, Z. y Turizo, M. (2015). Líneas de acción para prevenir y controlar la delincuencia juvenil en comunidades vulnerables de Barranquilla-Colombia y su área metropolitana. Justicia Juris, 11(1), 40-51.

Ministerio del Interior. (2018). Propuesta de Plan Nacional de Seguridad Ciudadana 2019 - 2023. Lima, Perú: Ministerio del Interior.

Montero, E., Villalobos, J. y Valverde, A. (2007). Factores institucionales, pedagógicos, psicosociales y sociodemográficos asociados al rendimiento académico en la Universidad de Costa Rica: Un análisis multinivel. Relieve, 13(2), 215-234.

OMS. (2002). Informe mundial de la violencia y la salud:resumen. Washington, D. C.: Organización Panamericana de la Salud.

Pichardo, C. (2014). Factores Psicosociales más frecuentes en adolescentes y jóvenes internas en el Centro Juvenil de privación de libertad para mujeres CEJUPLIM (tesis de maestría). Universidad Rafael Landívar, Nueva Guatemala de la Asunción, Guatemala.

Poblete, M. (2014). Identificación delictual juvenil: una propuesta de intervención ocupacional. Revista Chilena de Terapia Ocupacional, 14(1), 45-52.

Ramos, C. (2015). Los paradigmas de la investigación científica. Avances en Psicología, 23(1), 9-17.

Rodríguez, A. (2009). Delincuencia juvenil. Teoría y práctica de la investigación criminal (trabajo de investigación). Instituto Universitario General Gutiérrez Mellado-UNED, Madrid, España.

Rojas, A. (2013). Comportamiento integral y el bullying escolar en estudiantes de secundaria (tesis de maestría). Universidad San Martín de Porres, Lima, Perú.

Rojas, S. (23 de setiembre de 2014). La delincuencia juvenil aumenta en Lima. El Comercio, p. 1.

Salamea, D. (2014). Modelo de aplicación laboral que incorpore la prevención del estado ecuatoriano respecto de la delincuencia juvenil y el buen vivir (tesis de maestría). Universidad Regional Autónoma de los Andes, Ambato, Ecuador.

Salazar, T. (2014). Fundamentos políticos - criminales de la seguridad ciudadana en los lineamientos del estado peruano (tesis de doctorado). Universidad Mayor de San Marcos, Lima, Perú.

Sanabria, A. y Uribe, A. (2010). Factores psicosociales de riesgo asociados a conductas problemáticas en jóvenes infractores y no infractores. Perspectivas en Psicología, 6(2), 257 274. 
Sánchez, H. y Reyes, C. (2015). Metodología y diseños en la investigación científica. Lima, Perú: Business Support Aneth SRL, $5^{\text {ta }} \mathrm{ed}$.

Sánchez, I. (2013). Apoyo parental y rendimiento académico (tesis de maestría). Universidad Autónoma de Tamaulipas. Ciudad Victoria, México.

Sossa, R. (2010). Desintegración familiar y criminalidad. Revista de Ciencias Jurídicas, 124, 63 88.

Torres, T., Salazar, J., Reynaldos, C., Figueroa, N. y Araiza, A. (2011). Factores asociados a la delincuencia en adolescentes de Guadalajara, Jalisco. Papeles de población. Revista de la Universidad Autónoma del Estado de México, 68, 103-126.

Uceda, F. X., Navarro, J. J., y Pérez, J. V. (2016). Adolescentes y drogas: su relación con la delincuencia. Revista de Estudios Sociales, (58), 63-75.

UNODC. (2008). Informe Anual 2008: actividades de cobertura en 2007. Recuperado de http: / / www.unodc.org/documents/about-unodc/AR08_WEB.pdf, Viena.

Vacchelli, G. (2001). Delincuencia juvenil y consumo de drogas en el Perú. Recuperado de http: / / www2.congreso.gob.pe/sicr/cendocbib/con2_uibd.nsf/BBA20614AE1689CC052577 850073DE6C/ \$FILE/delincuencia-y-drogas.pdf.

Vanderschueren, F. y Lunecke, A. (2004). La Prevención del Delito en América Latina: Hacia una Evaluación. Apropiación de las experiencias internacionales. Políticas de Reducción de la Inseguridad en Europa, 86-133.

Wikström, P. O. H. \& Treiber, K. (2016). Situational Theory: The importance of interactions and actions mechanism in the explanation of crime. In A. Piquero. (Ed.), The Handbook of Criminological Theory (pp. 415-444). Sussex Occidental: Willey Blackwell.

Zamudio, A. (2015). Dimensiones de personalidad y conducta Infractora en Jóvenes de 16 a 20 años de edad, del Centro Juvenil de Diagnóstico y Rehabilitación de Lima (tesis de maestría). Universidad Nacional Mayor de San Marcos, Lima, Perú. 